\title{
High calcium diet alleviates 5/6 nephrectomy-induced bone deteriorations of lumbar vertebrae in mice
}

\author{
HAI-TAO HOU* ${ }^{*}$ YA-NAN WANG* ${ }^{*}$ SHI-ZE SHAO, SONG FU, XIANG-PENG HUANG and XIAO-HUI WANG \\ Department of Spinal and Spinal Cord Surgery, Shandong Wendeng Orthopedic Hospital, \\ Wendeng, Shandong 264400, P.R. China
}

Received July 12, 2017; Accepted November 3, 2017

DOI: $10.3892 /$ etm.2018.5866

\begin{abstract}
Dietary calcium (Ca) supplementation has beneficial effects on bone health. However, it is not clear whether a high calcium diet (HCD) following 5/6 nephrectomy (5/6 Nx) is beneficial to bone health. The aim of the present study was to examine the effects of an HCD on bone metabolism using a chronic kidney disease (CKD) mouse model. Male C57BL/6J mice were divided into three groups: Sham group, $5 / 6 \mathrm{Nx}$ group and 5/6 Nx + HCD group. Mice were sacrificed 12 weeks post-surgery. Calcium $(\mathrm{Ca})$ and creatinine $(\mathrm{Cr})$ were measured using standard colorimetric methods and picric acid methods, respectively. Bone metabolism-associated markers, FGF-23, PTH, ALP-b and TRAP-5b were measured using ELISA kits. Lumbar vertebrae histomorphological analysis was performed using hematoxylin and eosin staining. The expression of osteoprotegerin (OPG) and receptor activator of nuclear factor $\kappa \mathrm{B}$ ligand (RANKL) mRNA was detected using reverse transcription-quantitative polymerase chain reaction. Impaired renal function and histopathological damage was indicated in 5/6 Nx mice. However, HCD had no significant effects on these changes in 5/6 Nx mice. Notably, mineral metabolism disorder and histopathological damage to lumbar vertebrae were markedly improved in HCD-treated 5/6 Nx mice. Compared with 5/6 Nx mice, HCD supplementation significantly elevated the ratio of OPG/RANKL and inhibited RANKL mRNA expression in lumbar vertebrae. To conclude, the present findings indicated that increased $\mathrm{Ca}$ intake is effective in increasing bone mineral content of the lumbar vertebrae in 5/6 Nx mice. These results may provide a basis for the clinical use of dietary Ca supplementation as a therapeutic approach to treat $\mathrm{CKD}$-induced disturbance of mineral metabolism and bone loss.
\end{abstract}

Correspondence to: Dr Shi-Ze Shao, Department of Spinal and Spinal Cord Surgery, Shandong Wendeng Orthopedic Hospital, 1 Fengshan Road, Wendeng, Shandong 264400, P.R. China

E-mail: ss_ze88@163.com

${ }^{*}$ Contributed equally

Key words: high calcium diet, chronic kidney disease, bone injury

\section{Introduction}

Mineral and bone disorder (MBD) is a common complication associated with chronic kidney disease (CKD) (1). CKD-MBD is characterized by severe renal injury-induced mineral and hormone metabolic disorders accompanied by bone deteriorations (1). In the progression of CKD, low glomerular filtration rate (GFR) is associated with excessive phosphorus (P) levels, which accelerate osteocyte-derived fibroblast growth factor-23 (FGF-23) and parathyroid hormone (PTH) secretion and adversely affects bone remodeling and resorption, eventually resulting in osteoporotic bone complications (2). Previous clinical studies have demonstrated that the severity of CKD is associated with fracture rate $(3,4)$. Dysregulated mineral homeostasis is a typical feature of CKD $(3,4)$. Therefore, improving bone mineralization and microstructure in patients with CKD is necessary to reduce the risk of fracture.

Calcium (Ca) is important for bone health. Low $\mathrm{Ca}$ intake is associated with an increased risk of osteopenia and bone fractures, whereas high $\mathrm{Ca}$ intake has been indicated to protect against osteoporosis (5). Epidemiological studies have demonstrated that $\mathrm{Ca}$ supplementation has beneficial effects on bone mineral content and bone mineral density (BMD) (6,7). In rats, Ca supplementation prevented the bone loss and decline in kidney function induced by a high-P diet (8). Furthermore, a high calcium diet (HCD) increases bone mineral (Ca and $\mathrm{P}$ ) content in high-fat diet-induced obese mice (9). However, the effects of an HCD on CKD-induced bone have not previously been reported.

Previous studies have employed an 5/6 nephrectomy $(5 / 6 \mathrm{Nx})$ animal model to evaluate CKD-MBD $(10,11)$. At 16 weeks following $5 / 6 \mathrm{Nx}$, diminished bone microarchitecture was observed in the tibial trabecular bone of cluster of differentiation 1 mice (11), which is a well-established mouse model to produce moderate CKD with high-turnover bone injury. In the present study, a CKD-MBD animal model was established in C57BL/6J mice and the effects of an HCD on mineral homeostasis and trabecular bone properties were investigated.

\section{Materials and methods}

Animal model. The present study was approved by the Ethics Committee of Shandong Wendeng Orthopedic Hospital 
(Wendeng, China) and was performed in accordance with institutional guidelines. A total of 36 8-week-old male C57BL/6J mice (body weight, $20 \pm 2 \mathrm{~g}$ ) were obtained from Shanghai Laboratory Animal Center (Shanghai, China) and acclimated to the environment for 1 week. Normal dietary Ca (TD.04200, containing $0.6 \%$ calcium carbonate and $0.4 \%$ phosphate by weight) and high dietary Ca (TD.96348, containing $2 \%$ calcium carbonate and $1.25 \%$ phosphate by weight) were purchased from Harlan Teklad (Madison, WI, USA). The mice individually caged in a temperature-controlled environment $\left(23 \pm 2^{\circ} \mathrm{C}\right.$; humidity, $\left.60 \pm 5 \%\right)$ with an artificial 12-h light/dark cycle and were provided with free access to food and tap water. The 5/6 Nx mouse model of CKD was established without angiotensin II infusion according to the method published by Souza et al (12) and upregulation of blood urea nitrogen and serum creatinine verified successful establishment of the animal model (12). The mice were randomly divided into three groups $(n=12$ in each group): Sham group, sham-operated mice (without removal of kidneys) treated with normal dietary $\mathrm{Ca}$ following sham surgery for 12 weeks; 5/6 Nx group, 5/6 Nx mice treated with normal dietary $\mathrm{Ca}$ following $\mathrm{Nx}$ surgery for 12 weeks; and 5/6 Nx+HCD group, 5/6 Nx mice treated with HCD following Nx surgery for 12 weeks. All mice were sacrificed at week 12 via an intraperitoneal injection of sodium pentobarbital (200 mg/kg; Sigma-Aldrich; Merck KGaA, Darmstadt, Germany). Blood was harvested from the heart and centrifuged at $1,500 \mathrm{x}$ g for $15 \mathrm{~min}$ at $4^{\circ} \mathrm{C}$ to obtain serum. Serum $(\sim 800 \mu \mathrm{l})$, urine $(\sim 2 \mathrm{ml})$ and lumbar vertebrae (L3-L5) tissues were immediately collected and maintained at $-80^{\circ} \mathrm{C}$ for further analysis.

Biochemical markers in serum and urine. The concentrations of Ca (cat. no. C004-3; Nanjing Jiancheng Biology Engineering Institute, Nanjing, China) and creatinine $(\mathrm{Cr}$; cat. no. C011-1; Nanjing Jiancheng Biology Engineering Institute) from the serum and urine were measured using standard colorimetric methods (13) and picric acid methods (14), respectively. The level of urinary $\mathrm{Ca}$ (UCa) was corrected according to the concentration of urinary $\mathrm{Cr}$ ( $\mathrm{UCr}$ ). Serum Cr (SCr; cat. no. C011-1; Nanjing Jiancheng Biology Engineering Institute) and blood urea nitrogen (BUN; cat. no. C013-2; Nanjing Jiancheng Biology Engineering Institute) levels were measured using an autoanalyzer and an enzymatic kinetic method with commercial kits following the manufacturer's protocol. Serum levels of FGF-23 (cat. no. 60-6800; Immutopics, Inc., San Clemente, CA, USA), PTH (cat. no. E-EL-M0709c; Elabscience Biotechnology Co., Ltd., Wuhan, China), tartrate resistant acid phosphatase-5b (TRAP-5b; cat. no. SB-TR201A; Immunodiagnostic Systems, Scottsdale, AZ, USA) and alkaline phosphatase (ALP; cat. no. E-EL-M0200c; Elabscience Biotechnology Co., Ltd.) were detected using murine ELISA assays with a SpectraMax M5 ELISA plate reader (Molecular Devices, LLC, Sunnyvale, CA, USA).

Bone $\mathrm{Ca}$. The lumbar vertebrae were incinerated using a muffle furnace (Thermo Fisher Scientific, Inc., Waltham, MA, USA) at $800^{\circ} \mathrm{C}$ for $12 \mathrm{~h}$ and $10 \mathrm{mg}$ of bone ash was dissolved in $1 \mathrm{ml}$ of $37 \% \mathrm{HCl}$ diluted with Milli-Q ${ }^{\circledR}$ water. The calcium content was determined using a kit (cat. no. C004-3; Nanjing Jiancheng Biology Engineering Institute).

Histomorphology. Kidney tissues were collected immediately following sacrifice and fixed with $4 \%$ formalin at room temperature for $24 \mathrm{~h}$ and paraffin-embedded. Tissues were cut into $\sim 5 \mu \mathrm{m}$-thick sections, which were stained with Masson's trichrome (cat. no. SBJ-0290; Nanjing SenBeiJia Biological Technology Co., Ltd., Nanjing, China) as previously described (15) and visualized under a microscope (magnification, x200; Leica DM 2500; Leica Microsystems $\mathrm{GmbH}$, Wetzlar, Germany). Renal injury was assessed using a previously described $0-4$ scale (16) as follows: 0 , none; $1,<10$; $2,10-25 ; 3,25-75$; or $4,>75 \%$.

The lumbar vertebrae were collected immediately following sacrifice and fixed with $4 \%$ formalin at room temperature for $24 \mathrm{~h}$, and then decalcified in 0.5 M EDTA $(\mathrm{pH}=8.0)$ and embedded in paraffin according to standard histological procedures. Sections of $\sim 5 \mu \mathrm{m}$ were cut and stained with hematoxylin and eosin (H\&E; cat. no. C0105; Beyotime Institute of Biotechnology,) prior to being visualized under a microscope (magnification, x200; Leica DM 2500).

Reverse transcription-quantitative polymerase chain reaction $(R T-q P C R)$. Total RNA from lumbar vertebrae was extracted using TRIzol (Invitrogen; Thermo Fisher Scientific, Inc.) according to the manufacturer's protocol.cDNA was synthesized by RT reactions with $2 \mu \mathrm{g}$ of total RNA using moloney murine leukemia virus reverse transcriptase (Invitrogen; Thermo Fisher Scientific, Inc.) following $37^{\circ} \mathrm{C}$ for $50 \mathrm{~min}$ and $70^{\circ} \mathrm{C}$ for $15 \mathrm{~min}$. A total of $1 \mu \mathrm{l}$ cDNA was used for PCR using a DNA Engine (ABI) with SYBR Green PCR Master Mix (Invitrogen; Thermo Fisher Scientific, Inc.). The following thermocycling conditions were applied: $95^{\circ} \mathrm{C}$ for $10 \mathrm{~min}$ followed by 40 cycles of $95^{\circ} \mathrm{C}$ for $15 \mathrm{sec}, 58^{\circ} \mathrm{C}$ for $30 \mathrm{sec}$ and $72^{\circ} \mathrm{C}$ for $30 \mathrm{sec}$. The primers were synthesized by Sangon Biotech Co., Ltd. (Shanghai, China) as follows: osteoprotegerin (OPG), forward 5'-GCATTATGACCC AGAAACT-3' and reverse 5'-ACCTGAGAAGAACCCATC-3'; receptor activator of nuclear factor $\kappa B$ ligand (RANKL), forward 5'-AACCAAGATGGCTTCTATTACC-3' and reverse 5'-AAGGGTTGGACACCTGAATG-3'; and GAPDH, forward 5'-TCACTGCCACCCAGAAGA-3' and reverse 5'-AAGTCG CAGGAGACAACC-3'. Signals were assessed using Quantity One ${ }^{\circledR}$ software version 4.5 (Bio Rad Laboratories, Inc., Hercules, CA, USA) and normalized to the GAPDH. Analysis of relative gene expression data used real-time quantitative PCR and the quantitation cycle $(\mathrm{Cq})$ method (17).

Statistical analysis. Data are presented as the mean + or \pm standard deviation as indicated for each group. All statistical analyses were performed using GraphPad Prism software version 5.0 (GraphPad Software, Inc., La Jolla, CA, USA). Inter-group differences were analyzed using one-way analysis of variance with a post hoc Tukey test for multiple comparisons. $\mathrm{P}<0.05$ was considered to indicate a statistically significant difference.

\section{Results}

HCD supplementation has no significant effect on renal dysfunction in 5/6 Nx mice. To evaluate the role of HCD 


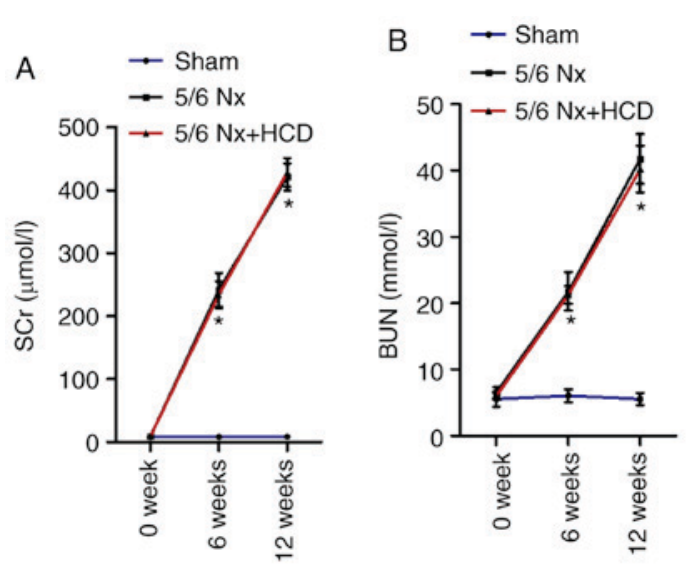

C
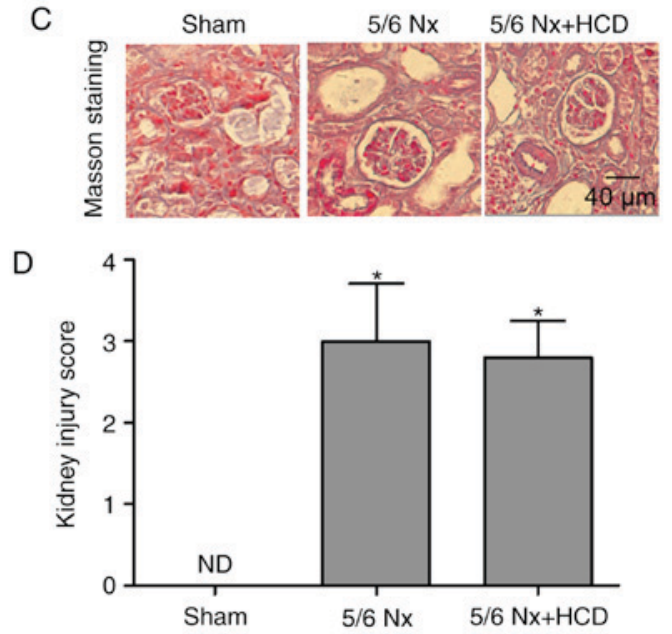

Figure 1. Changes in renal function in 5/6 Nx mice. (A) SCr and (B) BUN levels in 5/6 Nx mice with or without HCD supplementation were measured. Data are presented as the mean \pm standard deviation. (C) Masson's trichrome staining was performed in 5/6 Nx mice with or without HCD supplementation to evaluate renal injury (magnification, x200). (D) Kidney injury score for each group. Data are presented as the mean \pm standard deviation. ${ }^{*} \mathrm{P}<0.05$ vs. Sham group. 5/6 Nx, 5/6 nephrectomy; SCr, serum creatinine; BUN, blood urea nitrogen; HCD, high calcium diet; ND, not detected.

supplementation in 5/6 Nx-induced renal dysfunction, serum levels of $\mathrm{SCr}$ and BUN were compared across groups. The levels of $\mathrm{SCr}$ and $\mathrm{BUN}$ were significantly increased in the $5 / 6 \mathrm{Nx}$ group compared with the sham-operated group at week 6 and week 12 $(\mathrm{P}<0.05$; Fig. 1A and B); however, HCD supplementation in 5/6 Nx mice did not significantly improve these parameters (Fig. 1A and B). Masson staining was performed to observe the extent of renal interstitial fibrosis. As indicated in Fig. 1C and D, increased matrix deposition, interstitial fibrosis and renal lesions were observed in the kidneys from 5/6 Nx mice compared with sham mice, and injury scores were significantly increased $(\mathrm{P}<0.05$; Fig. 1D). Furthermore, HCD supplementation had no marked effect on renal pathological changes in 5/6 Nx mice. These data suggest that the CKD mice models were successfully established and that HCD did not improve renal function in 5/6 Nx mice.

HCD supplementation regulates bone metabolism-associated biomarkers. Acute kidney injury (AKI) or CKD-induced GFR regression predisposes to bone metabolism disturbances via upregulating serum $\mathrm{P}$ (18), which accelerates FGF-23 and PTH secretion. Previous studies have demonstrated that increased FGF-23 is associated with CKD or AKI severity $(19,20)$.
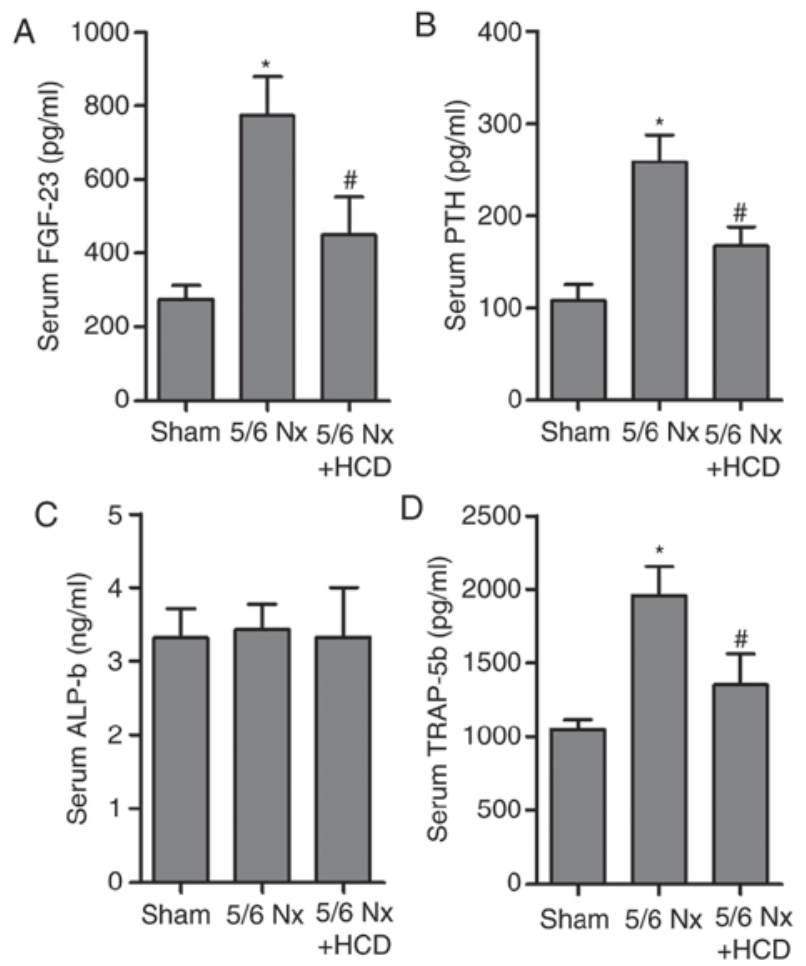

Figure 2. HCD supplementation regulates bone metabolism-associated biomarkers. Serum levels of (A) FGF-23, (B) PTH, (C) ALP and (D) TRAP-5b mice were measured in 5/6 Nx with or without HCD supplementation. Data are presented as the mean \pm standard deviation. ${ }^{*} \mathrm{P}<0.05$ vs. Sham group; ${ }^{\#} \mathrm{P}<0.05$ vs. $5 / 6 \mathrm{Nx}$ group. $5 / 6 \mathrm{Nx}, 5 / 6$ nephrectomy; HCD, high calcium diet; FGF-23, fibroblast growth factor-23; PTH, parathyroid hormone; ALP, alkaline phosphatase; TRAP-5b, tartrate resistant acid phosphatase-5b.

FGF-23 is a peptide released from osteocytes and osteoblasts, whilst PTH is associated with $\mathrm{Ca}, \mathrm{P}$ and FGF-23 levels in CKD (21). To evaluate the effect of an HCD in CKD-MBD, the levels of FGF-23 and PTH in the serum of 5/6 Nx mice were measured. Results indicated that serum FGF-23 and PTH levels were significantly increased in the 5/6 Nx group compared with the sham group $(\mathrm{P}<0.05$; Fig. $2 \mathrm{~A}$ and $\mathrm{B})$. Notably, HCD significantly reversed CKD-induced upregulation of serum FGF-23 and PTH levels in 5/6 Nx mice $(\mathrm{P}<0.05$; Fig. 2A and B). In addition, the effect of $5 / 6 \mathrm{Nx}$ on markers of bone resorption and formation, ALP and TRAP-5b $(22,23)$, in the serum of 5/6 Nx mice was assessed (Fig. 2C and D). $5 / 6 \mathrm{Nx}$ induced a significant increase in serum TRAP-5b concentration compared with the sham group; however, HCD supplementation significantly decreased TRAP-5b levels in CKD mice $(\mathrm{P}<0.05)$. No significant difference in ALP concentration was observed in any of the experimental groups.

HCD supplementation regulates Ca metabolism and bone remodeling. $\mathrm{HCD}$ has an important role in the bone-kidney axis and the regulation of calcium homeostasis in $\operatorname{CKD}(24,25)$. The $\mathrm{Ca}$ content in serum, urine and bone was measured in CKD mice. Results indicated that 5/6 Nx mice exhibited decreased $\mathrm{SCa}$ levels and an $\sim 3$-fold increase in UCa excretion compared with the sham group, whereas HCD supplementation significantly increased SCa content and decreased UCa excretion in CKD mice ( $\mathrm{P}<0.05$; Fig. 3A and B). At week 12, comparison of the results of bone $\mathrm{Ca}$ content between sham and 5/6 Nx groups 

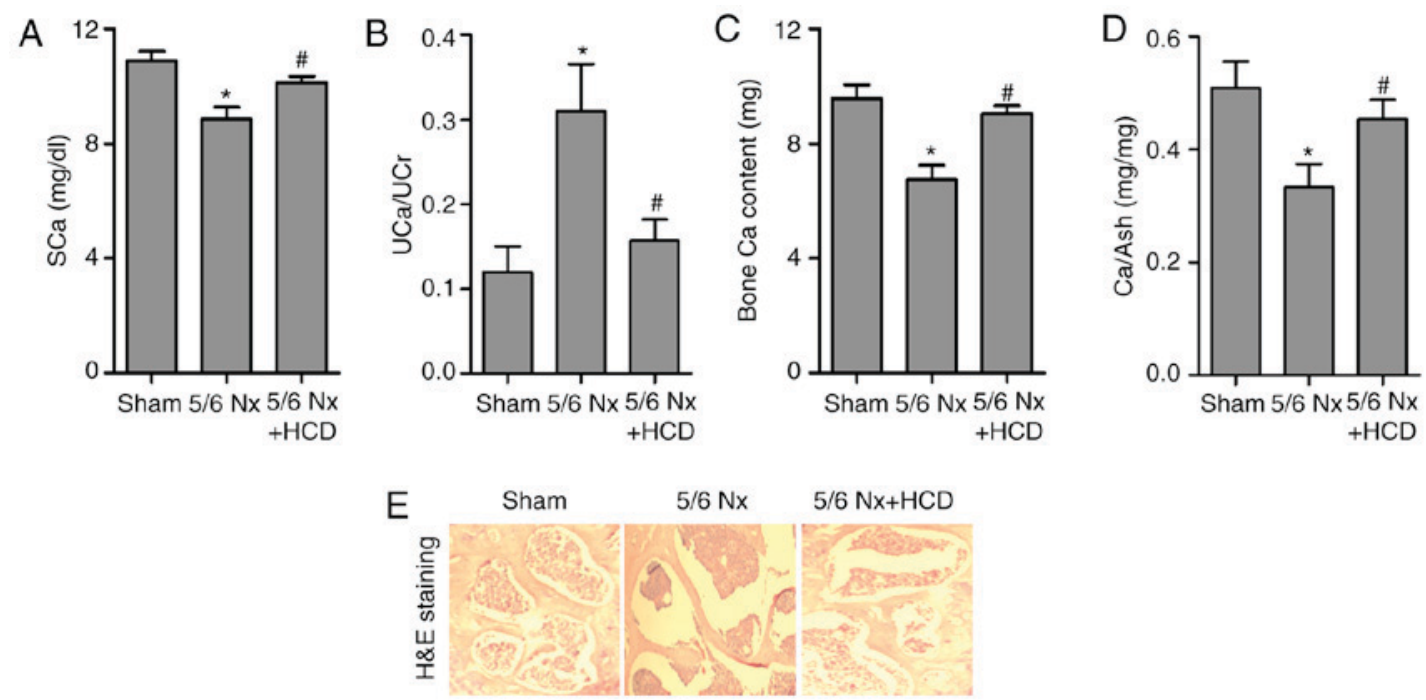

Figure 3. HCD supplementation regulates Ca metabolism and bone remodeling. Concentrations of (A) SCa (B) UCa, (C) bone Ca and (D) Ca/Ash were measured in 5/6 Nx mice with or without HCD supplementation. (E) H\&E staining (magnification, x200) was performed in 5/6 Nx mice with or without HCD supplementation to evaluate trabecular bone injury. Data are presented as the mean \pm standard deviation* $\mathrm{P}<0.05$ vs. Sham group; ${ }^{*} \mathrm{P}<0.05$ vs. $5 / 6 \mathrm{Nx}$ group. 5/6 Nx, 5/6 nephrectomy; Ca, calcium; SCa, serum calcium; UCa, urinary Ca; HCD, high calcium diet; H\&E, hematoxylin \& eosin.

indicated 5/6 Nx significantly decreased bone Ca content; however, the bone calcium content was significantly increased in 5/6 Nx mice with $\mathrm{HCD}$ supplementation (both $\mathrm{P}<0.05$; Fig. 3C). A similar result was obtained for $\mathrm{Ca}$ content in the ash of lumbar vertebrae (Fig. 3D). Furthermore, H\&E staining was conducted to observe the trabecular bone microstructure of lumbar vertebrae. As indicated in Fig. 3E, a loss of network connection in the trabecular bone was observed in the $5 / 6 \mathrm{Nx}$ group compared with the sham group; however, the increased disconnections and separation among trabecular bone network were improved by HCD supplementation in CKD mice.

$H C D$ supplementation regulates the OPG/RANKL ratio. The maturation and formation of osteoclasts is primarily regulated by the balance of extracellular OPG and RANKL (26). OPG and RANKL cytokines affect the activity of osteoblast cells and osteoclastogenesis (26). OPG cytokine binds to RANKL and prevents RANKL from binding to the RANK receptor on osteoclast cells, subsequently inhibiting bone resorption and osteoclastogenesis (27). Thus, the ratio of OPG/RANKL expression in lumbar vertebrae was determined in the present study (Fig. 4). RT-qPCR results revealed a significant decrease in the OPG mRNA expression levels and ratio of OPG/RANKL compared with the sham group $(\mathrm{P}<0.05$; Fig. $4 \mathrm{~A}, \mathrm{~B}$ and $\mathrm{D})$. Furthermore, RANKL mRNA expression levels were significantly increased in mice treated with 5/6 Nx compared with the sham group ( $\mathrm{P}<0.05$; Fig. $4 \mathrm{~A}$ and $\mathrm{C})$. HCD supplementation significantly reversed the effects of $5 / 6 \mathrm{Nx}$ on OPG/RANKL and RANKL mRNA expression ( $\mathrm{P}<0.05$; Fig. $4 \mathrm{C}$ and $\mathrm{D})$. However, no significant difference was observed between the mRNA expression levels of OPG in the 5/6 Nx and 5/6 Nx + HCD groups.

\section{Discussion}

Patients with CKD exhibit marked disruptions in bone and mineral metabolism accompanied with biochemical alterations, including elevated FGF-23 and PTH, decreased 1,
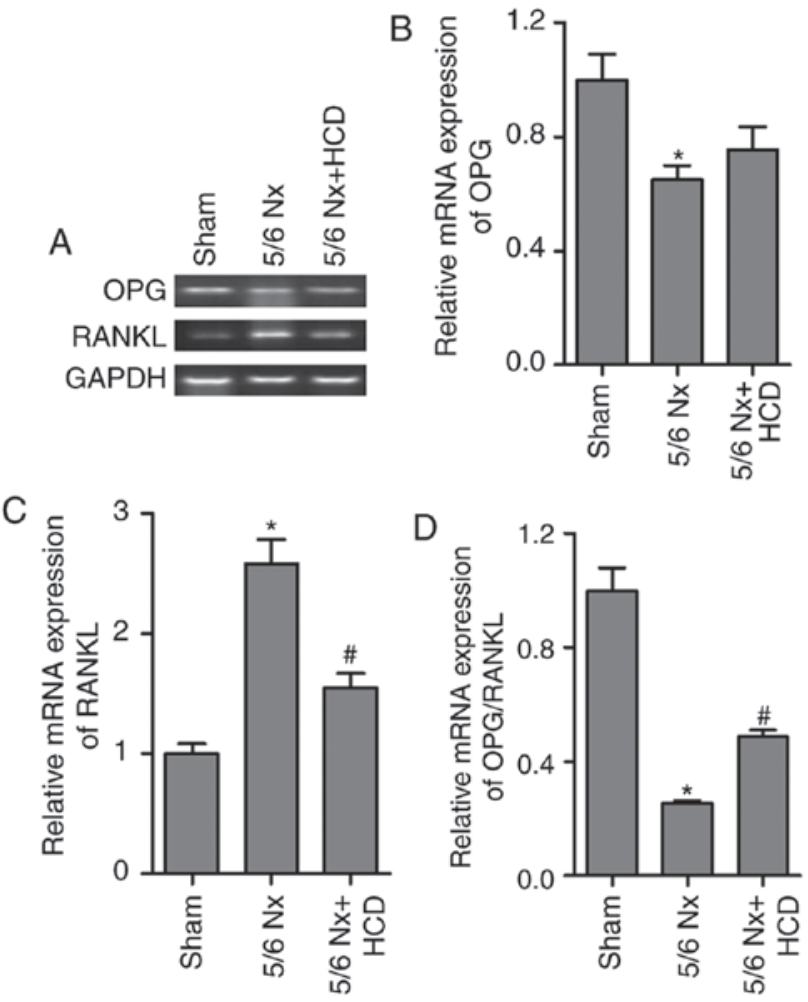

Figure 4. HCD supplementation regulated OPG/RANKL ratio. (A) mRNA expression levels of OPG and RANKL were determined. Quantified results of the mRNA expression levels of (B) OPG and (C) RANKL and (D) the ratio of OPG/RANKL were demonstrated in 5/6 Nx mice with or without HCD supplementation. Data are presented as the mean \pm standard deviation. ${ }^{*} \mathrm{P}<0.05$ vs. Sham group; ${ }^{\text {}} \mathrm{P}<0.05$ vs. $5 / 6 \mathrm{Nx}$ group. OPG/RANKL; osteoprotegerin/receptor activator of nuclear factor kappa B ligand; 5/6 Nx, 5/6 nephrectomy; HCD, high calcium diet.

25-dihydroxyvitamin D3 (vitamin D3), elevated serum P and decreased $\mathrm{SCa}$ (28). Oral Ca carbonate affects the positive $\mathrm{Ca}$ balance in stage 3 and 4 CKD (29). Ca (1,200 mg) combined with vitamin D3 (800 IU) supplementation protects against 
BMD loss in women with moderate CKD (30). Furthermore, dietary $\mathrm{Ca}$ supplementation has been indicated to prevent bone loss in several animal models, notably ovariectomized and renal injury rodents $(31,32)$. These findings suggest that dietary Ca supplementation may serve as an adjunctive therapy for CKD-induced bone loss.

The lumbar vertebra is a hypersensitive site that is susceptible to bone injury (33). In clinical practice, kidney transplant recipients have a lower lumbar spine trabecular bone score, which is associated with an increased incidence of fractures (34). This suggests that Nx is associated with lumbar vertebrae injury. In the present study, 5/6 Nx significantly decreased SCa content and increased serum PTH and FGF-23 concentration. It is known that PTH stimulates the expression of RANKL, a mediator of osteoclastogenesis and bone resorption (35). In the present study, it was observed that RANKL mRNA expression was significantly increased and OPG mRNA expression was decreased in the lumbar vertebrae of 5/6 Nx mice compared with the sham group. These findings indicate that bone resorption and bone loss are enhanced in mice following 5/6 Nx. However, HCD supplementation significantly increased $\mathrm{SCa}$, bone Ca content and $\mathrm{Ca} / \mathrm{Ash}$, whilst bone loss of lumbar vertebrae in 5/6 Nx mice was ameliorated. A previous study indicated that dietary $\mathrm{Ca}$ supplementation inhibits RANKL-mediated osteoclastic bone resorption via the suppression of PTH (8). Thus, these findings suggest that HCD supplementation may increase bone $\mathrm{Ca}$ content and bone remodeling via inhibiting RANKL-induced bone resorption in 5/6 Nx mice. Piri et al (36) assessed the levels of OPG and RANKL associated with dietary supplements of $\mathrm{Ca}$, vitamin $\mathrm{D}$ and estrogen, revealing that $\mathrm{Ca}$ intake led to an increase in OPG and reduction in RANKL, which ultimately caused an increase in BMD. According to the results of the present study, OPG/RANKL signaling is associated with 5/6 Nx-induced bone deterioration of lumbar vertebrae in mice, which suggests that OPG/RANKL may be an important target for the treatment of CKD-induced bone injury.

FGF-23 is a member of the fibroblast growth factor family and is associated with $\mathrm{P}$ homeostasis (37). A recent study has revealed that $\mathrm{Ca}$ regulates bone FGF-23 expression and that HCD increases serum FGF-23 concentration in Cyp27b1 ${ }^{-/-}$and $\mathrm{Gcm}^{-/-}$mice (38). In parathyroidectomized rats, dietary $\mathrm{Ca}$ supplementation increased SCa and FGF-23 concentration (39). However, Ca has no effect on FGF-23 promoter activity in cultured osteoblasts (40). Furthermore, it has been reported that serum FGF-23 concentration is positively correlated with serum P levels (41). In the present study, 5/6 Nx mice had high serum P levels, which was associated with high serum FGF-23 despite hypocalcemia. These data suggest that Ca regulation of FGF-23 expression is also controversial. In the present study, it was identified that dietary $\mathrm{Ca}$ supplementation significantly decreased serum $\mathrm{P}$ and FGF-23 in CKD mice.

$\mathrm{Ca}$ and $\mathrm{P}$ are substrates for bone mineralization that are tightly regulated by several hormones, including FGF-23, PTH and vitamin D3 (42). Dysregulation of one hormone in this system results in the dysregulation of $\mathrm{Ca}$ and $\mathrm{P}$ homeostasis; particularly, active vitamin D synthesis is stimulated by hypophosphatemia in the kidney (42). FGF-23 is increased in the primary stage of CKD; however, renal tubular injury accelerates FGF23 secretion and results in a decrease in serum vitamin D3 levels, which in turn increases serum phosphate and decreases ionized $\mathrm{Ca}$ (43). In a clinical setting, foods rich in $\mathrm{Ca}$ and low in phosphate are permitted in patients with CKD (44). In the present study of 5/6 Nx mice with CKD, serum FGF-23 and PTH were significantly decreased, whereas serum $\mathrm{Ca}$ and bone $\mathrm{Ca}$ were increased in response to dietary Ca supplementation, ameliorating CKD-induced network connection loss in trabecular bone.

In conclusion, these findings provide a novel insight into the pathophysiological and nutritional role of an HCD in the regulation of $\mathrm{Ca}$ homeostasis and bone metabolism-associated hormones in 5/6 Nx mice. In addition, HCD has an anabolic potential to enhance novel bone formation and suppress bone resorption in $5 / 6 \mathrm{Nx}$ mice. The present study provides the theory base for dietary $\mathrm{Ca}$ supplementation beneficial for the balance of bone metabolism in patients with CKD. However, cross-sectional and longitudinal studies are required to elaborate the standards, rules and alimental interaction in routine clinical practice.

\section{References}

1. Lin W, Li Y, Chen F, Yin S, Liu Z and Cao W: Klotho preservation via histone deacetylase inhibition attenuates chronic kidney disease-associated bone injury in mice. Sci Rep 7: 46195, 2017.

2. Kochanek M, Said A and Lerma EV: Mineral metabolism in chronic kidney disease. Dis Mon 61: 425-433, 2015.

3. Naylor KL, McArthur E, Leslie WD, Fraser LA, Jamal SA, Cadarette SM, Pouget JG, Lok CE, Hodsman AB, Adachi JD and Garg AX: The three-year incidence of fracture in chronic kidney disease. Kidney Int 86: 810-818, 2014.

4. El Desoky S, Farag YM, Safdar E, Shalaby MA, Singh AK and Kari JA: Prevalence of hyperparathyroidism, mineral and bone disorders in children with advanced chronic kidney disease. Indian J Pediatr 83: 420-425, 2016.

5. Song Q and Sergeev IN: Calcium and vitamin D in obesity. Nutr Res Rev 25: 130-141, 2012.

6. Johnston CC Jr, Miller JZ, Slemenda CW, Reister TK, Hui S, Christian JC and Peacock M: Calcium supplementation and increases in bone mineral density in children. N Engl J Med 327: 82-87, 1992.

7. Lee WT, Leung SS, Wang SH, Xu YC, Zeng WP, Lau J, Oppenheimer SJ and Cheng JC: Double-blind, controlled calcium supplementation and bone mineral accretion in children accustomed to a low-calcium diet. Am J Clin Nutr 60: 744-750, 1994.

8. Katsumata S, Matsuzaki H, Uehara M and Suzuki K: Effects of dietary calcium supplementation on bone metabolism, kidney mineral concentrations, and kidney function in rats fed a high-phosphorus diet. J Nutr Sci Vitaminol (Tokyo) 61: 195-200, 2015.

9. Song Q and Sergeev IN: High vitamin D and calcium intakes increase bone mineral ( $\mathrm{Ca}$ and $\mathrm{P})$ content in high-fat diet-induced obese mice. Nutr Res 35: 146-154, 2015.

10. Ferrari GO, Ferreira JC, Cavallari RT, Neves KR, dos Reis LM, Dominguez WV, Oliveira EC, Graciolli FG, Passlick-Deetjen J, Jorgetti V and Moysés RM: Mineral bone disorder in chronic kidney disease: Head-to-head comparison of the 5/6 nephrectomy and adenine models. BMC Nephrol 15: 69, 2014.

11. Heveran CM, Ortega AM, Cureton A, Clark R, Livingston EW, Bateman TA, Levi M, King KB and Ferguson VL: Moderate chronic kidney disease impairs bone quality in $\mathrm{C} 57 \mathrm{Bl} / 6 \mathrm{~J}$ mice. Bone 86: 1-9, 2016

12. Souza AC, Tsuji T, Baranova IN, Bocharov AV, Wilkins KJ, Street JM, Alvarez-Prats A, Hu X, Eggerman T, Yuen PS and Star RA: TLR4 mutant mice are protected from renal fibrosis and chronic kidney disease progression. Physiol Rep 3: e12558, 2015.

13. Löwe A, Breuer J and Palkowitsch P: Evaluation of the effect of two gadolinium-containing contrast-enhancing agents, gadobutrol and gadoxetate disodium, on colorimetric calcium determinations in serum and plasma. Invest Radiol 46: 366-369, 2011. 
14. Massoomi F, Mathews HG III and Destache CJ: Effect of seven fluoroquinolones on the determination of serum creatinine by the picric acid and enzymatic methods. Ann Pharmacother 27: $586-588,1993$

15. Sun D, Feng J, Dai C, Sun L, Jin T, Ma J and Wang L: Role of peritubular capillary loss and hypoxia in progressive tubulointerstitial fibrosis in a rat model of aristolochic acid nephropathy. Am J Nephrol 26: 363-371, 2006.

16. Fan HY, Qi D, Yu C, Zhao F, Liu T, Zhang ZK, Yang MY, Zhang LM, Chen DQ and Du Y: Paeonol protects endotoxin-induced acute kidney injury: Potential mechanism of inhibiting TLR4-NF-kappaB signal pathway. Oncotarget 7: 39497-39510, 2016.

17. Livak KJ and Schmittgen TD: Analysis of relative gene expression data using real-time quantitative PCR and the 2(-Delta Delta C(T)) method. Methods 25: 402-408, 2001

18. Kakareko K, Rydzewska-Rosolowska A, Brzosko S, Gozdzikiewicz-Lapinska J, Koc-Zorawska E, Samocik P, Kozlowski R, Mysliwiec M, Naumnik B and Hryszko T: The effect of nephrectomy on Klotho, FGF-23 and bone metabolism. Int Urol Nephrol 49: 681-688, 2017.

19. Nitta K, Nagano N and Tsuchiya K: Fibroblast growth factor 23/klotho axis in chronic kidney disease. Nephron Clin Pract 128: 1-10, 2014

20. Christov M, Waikar SS, Pereira RC, Havasi A, Leaf DE, Goltzman D, Pajevic PD, Wolf M and Jüppner H: Plasma FGF23 levels increase rapidly after acute kidney injury. Kidney Int 84 776-785, 2013

21. Lavi-Moshayoff V, Wasserman G, Meir T, Silver J and Naveh-Many T: PTH increases FGF23 gene expression and mediates the high-FGF23 levels of experimental kidney failure: A bone parathyroid feedback loop. Am J Physiol Renal Physiol 299: F882-F889, 2010.

22. Wu Y, Lee JW, Uy L, Abosaleem B, Gunn H, Ma M and DeSilva B: Tartrate-resistant acid phosphatase (TRACP 5b): A biomarker of bone resorption rate in support of drug development: Modification, validation and application of the BoneTRAP kit assay. J Pharm Biomed Anal 49: 1203-1212, 2009.

23. An J, Yang H, Zhang Q, Liu C, Zhao J, Zhang L and Chen B Natural products for treatment of osteoporosis: The effects and mechanisms on promoting osteoblast-mediated bone formation. Life Sci 147: 46-58, 2016.

24. Haussler MR, Whitfield GK, Kaneko I, Forster R, Saini R, Hsieh JC, Haussler CA and Jurutka PW: The role of vitamin D in the FGF23, klotho, and phosphate bone-kidney endocrine axis. Rev Endocr Metab Disord 13: 57-69, 2012.

25. Martin A and Quarles LD: Evidence for FGF23 involvement in a bone-kidney axis regulating bone mineralization and systemic phosphate and vitamin D homeostasis. Adv Exp Med Biol 728 65-83, 2012.

26. Pitari MR, Rossi M, Amodio N, Botta C, Morelli E, Federico C, Gullà A, Caracciolo D, Di Martino MT, Arbitrio M, et al: Inhibition of miR-21 restores RANKL/OPG ratio in multiple myeloma-derived bone marrow stromal cells and impairs the resorbing activity of mature osteoclasts. Oncotarget 6: 27343-27358, 2015.

27. Walsh MC and Choi Y: Biology of the RANKL-RANK-OPG system in immunity, bone, and beyond. Front Immunol 5: 511, 2014.

28. Hill Gallant KM and Spiegel DM: Calcium balance in chronic kidney disease. Curr Osteoporos Rep 15: 214-221, 2017.
29. Hill KM, Martin BR, Wastney ME, McCabe GP, Moe SM, Weaver CM and Peacock M: Oral calcium carbonate affects calcium but not phosphorus balance in stage 3-4 chronic kidney disease. Kidney Int 83: 959-966, 2013

30. Bosworth C, de Boer IH, Targher G, Kendrick J, Smits G and Chonchol M: The effect of combined calcium and cholecalciferol supplementation on bone mineral density in elderly women with moderate chronic kidney disease. Clin Nephrol 77: 358-365, 2012.

31. Charoenphandhu N, Tudpor K, Thongchote K, Saengamnart W, Puntheeranurak S and Krishnamra N: High-calcium diet modulates effects of long-term prolactin exposure on the cortical bone calcium content in ovariectomized rats. Am J Physiol Endocrinol Metab 292: E443-E452, 2007.

32. Fonseca D and Ward WE: Daidzein together with high calcium preserve bone mass and biomechanical strength at multiple sites in ovariectomized mice. Bone 35: 489-497, 2004.

33. Naitoh M, Takada ST, Kurosu Y, Inagaki K, Mitani A and Ariji E: Relationship between findings of mandibular cortical bone in inferior border and bone mineral densities of lumbar vertebrae in postmenopausal women. Okajimas Folia Anat Jpn 91: 49-55, 2014.

34. Naylor KL, Lix LM, Hans D, Garg AX, Rush DN, Hodsman AB and Leslie WD: Trabecular bone score in kidney transplant recipients. Osteoporos Int 27: 1115-1121, 2016.

35. van Heerden B, Kasonga A, Kruger MC and Coetzee M: Palmitoleic acid inhibits RANKL-induced osteoclastogenesis and bone resorption by suppressing NF-kappaB and MAPK signalling pathways. Nutrients 9: E441, 2017.

36. Piri F, Khosravi A, Moayeri A, Moradipour A and Derakhshan S: The effects of dietary supplements of calcium, vitamin D and estrogen hormone on serum levels of OPG and RANKL cytokines and their relationship with increased bone density in Rats. J Clin Diagn Res 10: AF01-AF04, 2016.

37. Stubbs J, Liu S and Quarles LD: Role of fibroblast growth factor 23 in phosphate homeostasis and pathogenesis of disordered mineral metabolism in chronic kidney disease. Semin Dial 20: 302-308, 2007.

38. David V, Dai B, Martin A, Huang J, Han X and Quarles LD: Calcium regulates FGF-23 expression in bone.Endocrinology 154: 4469-4482, 2013.

39. Rodriguez-Ortiz ME, Lopez I, Muñoz-Castañeda JR, Martinez-Moreno JM, Ramírez AP, Pineda C, Canalejo A, Jaeger P, Aguilera-Tejero E, Rodriguez M, et al: Calcium deficiency reduces circulating levels of FGF23. J Am Soc Nephrol 23: 1190-1197, 2012

40. Liu S, Tang W, Zhou J, Stubbs JR, Luo Q, Pi M and Quarles LD: Fibroblast growth factor 23 is a counter-regulatory phosphaturic hormone for vitamin D. J Am Soc Nephrol 17: 1305-1315, 2006.

41. Imanishi Y, Inaba M, Nakatsuka K, Nagasue K, Okuno S, Yoshihara A, Miura M, Miyauchi A, Kobayashi K, Miki T, et al: FGF-23 in patients with end-stage renal disease on hemodialysis. Kidney Int 65: 1943-1946, 2004.

42. Penido MGMG and Alon US: Phosphate homeostasis and its role in bone health. Pediatr Nephrol 27: 2039-2048, 2012.

43. Nickolas TL and Jamal SA: Bone kidney interactions. Rev Endocr Metab Disord 16: 157-163, 2015.

44. Spiegel DM and Brady K: Calcium balance in normal individuals and in patients with chronic kidney disease on low- and high-calcium diets. Kidney Int 81: 1116-1122, 2012. 